\title{
THE 2019 TEXAS COASTAL RESILIENCY MASTER PLAN
}

\author{
Chris Levitz,AECOM, chris.levitz@aecom.com
}

In 2017, the Texas General Land Office (GLO) released the first Texas Coastal Resiliency Master Plan, an ambitious coastal planning effort to restore, enhance and protect more than 367 miles of coast and some 3,300 miles of bays and estuaries for the State of Texas. The lynchpin of the planning effort is its emphasis on shoring up the coast by using the latest coastal technology backed by research on Texas coastal environments, coastal hydrodynamics and morphology, and sediment supply, among others, in conjunction with federal, public, and private entity coordination. By championing a statewide Plan to guide the future of coastal management, the GLO will assure that Texas continues to restore, enhance, and protect its coastlines and communities.

\section{THE FUTURE OF COASTAL MANAGEMENT}

The coast of Texas is home to over 6.5 million people and $\$ 600$ billion of real property. Texas ports pass over 22 percent of the nation's annual port tonnage, and are the backbone of the nation's energy industry, supporting Texas oil and gas extraction, which totals 57 percent of the country's value added in that market. Working towards the second publication of the Texas Coastal Resiliency Master Plan in 2019, the GLO, in collaboration with AECOM and the Harte Research Institute, will look at coastal data and trends in areas such as shoreline erosion, freshwater inflows, and sediment transport to plan and begin policy advancement, beach nourishment, and ecological restoration to advance coastal community resiliency. In addition to working with coastal and marine scientists and engineers, the GLO will also coordinate with a Technical Advisory Committee to advance responsible coastal community planning to better prepare for and respond to coastal hazards. By presenting results from data collection and stakeholder feedback, the 2019 Plan will help local, state, and federal decision makers to understand the value provided by the coast, the inherent risks these coastal communities and resources face and the associated opportunities to manage a dynamic coastal environment in a more resilient manner.

\section{ADAPTING TO THE COASTAL ENVIRONMENT}

The Texas General Land Office understands that the Texas Gulf Coast is a dynamic and changing environment. The multitude of investigations conducted by the world's top coastal researchers point to a future Texas coast that has already been and will continue to be susceptible to sea level rise, subsidence, and erosion. In order to plan for changing future scenarios, the GLO will look towards understanding probable changes to the coastal environment that can be addressed by forward thinking ecological planning, monitoring, and adaptive management. As just one example, the 2019 Plan will look at future impacts on sensitive coastal habitats, such as its estuarine wetlands, to determine at-risk areas and mitigation strategies. Addressing needs of the natural coastal systems will also open the door for new solutions to help Texas's coastal communities develop as responsible stewards of their coastal assets. Project solutions identified in the Texas Coastal Resiliency Master Plan that can mitigate or eliminate these concerns in a feasible and cost-effective manner are considered the most resilient solutions for the coast that will strengthen the GLO's goal of protecting, restoring and enhancing the Texas coast.

\section{ADVANCING COASTAL RESILIENCY}

The 2019 Plan will build upon the 2017 Plan to look at community infrastructure improvements through the lens of coastal resiliency. Taking current and proposed coastal infrastructure projects, such as coastal highway and evacuation route improvements, the GLO will work to promote ecologically resilient construction elements that allow future infrastructure to provide multiple lines of defense enhancements to the Texas coast. The 2019 Texas Coastal Resiliency Master Plan will also better position the GLO to manage, distribute and implement projects and funding for pre-disaster planning or postdisaster response.

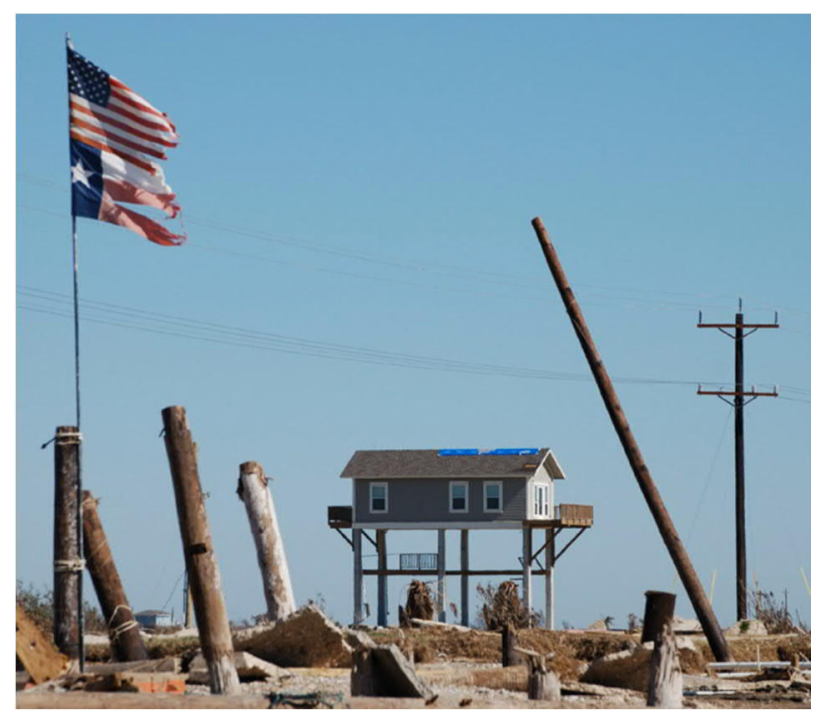

Figure 1 - Bolivar Peninsula, Texas after Hurricane Ike

\section{TEXAS COSTAL RESILIENCY: A BIGGER FUTURE}

The State of Texas is vulnerable to natural disasters that endanger the lives of its citizens and have crippling effects on both the state and national economies. In its two most recent hurricanes, Hurricane Ike (see Figure 1) in 2008 and Hurricane Harvey in 2017, the state has faced the enormous task of deciding how to rebuild its coastal frontier to be stronger and more resilient than ever before. The ultimate goal of the Texas Coastal Resiliency Master Plan is a better and safer future for all Texans in the path of coastal vulnerabilities and natural disasters. As the 2019 P lan moves forward, the GLO will incorporate lessons learned from Hurricane Harvey and seek opportunities to embolden the state to become global leaders in the field of coastal recovery and protection. 